\title{
当科における人工膝関節置換術の長期成績
}

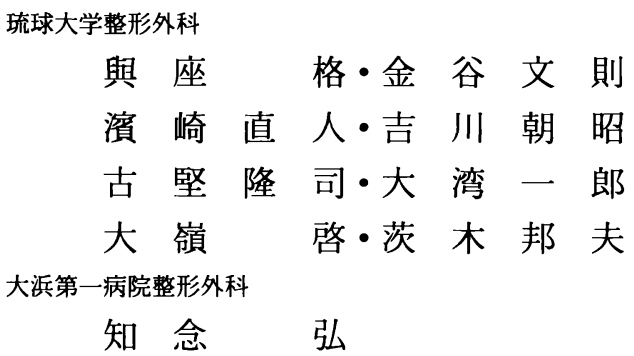

\section{Long-term Results of Total Knee Arthroplasty}

\section{Tadashi Yoza, Fuminori Kanaya, Naoto Hamasaki, Tomoaki Yoshikawa, Takashi Furugen, Ichiro Owan, Akira Ohmine, and Kunio Ibaraki}

Department of Orthopedic Surgery, School of Medicine, University of the Ryukyus

\section{Hiroshi Chinen}

Department of Orthopedic Surgery, Ohama Daiichi Hospital

\begin{abstract}
We report long-term results (over 10 years) of total knee arthroplasty (TKA) for the treatment of osteoarthritis (OA) and rheumatoid arthritis (RA). Twenty-three patients (OA; 10 patients, RA ; 13 patients) with 36 knees were examined. Clinical results were evaluated using the Knee Function Scoring System developed by three universities. Radiographs were evaluated for the loosening and sinking of TKA. Post-operative complications were evaluated in 79 knees of 49 patients.

The function score significantly improved from 41 to 73 points in patients with OA and from 40 to 63 points in patients with RA. In both OA and RA knees, the extension of the knee joint improved after surgery and was maintained at follow-up. Positive correlation was found between the knee flexion angle before surgery and that at follow-up. In radiographic evaluation, only 1 sinking was found in OA, whereas, 2 loosening and 4 sinking were found in RA. Postoperative complications were 1 infection in OA, whereas, 7 aseptic loosening, 2 infections, and 1 posterior dislocation were seen in RA, indicating better functional recovery with less complication can be expected in OA patients than in RA patients. Better flexion of the knee joint can also be expected if TKA is performed before contracture of the knee joints develops.
\end{abstract}

Key words : Total knee arthroplasty (人工膝関節置換術), rheumatoid arthritis (慢性関節リウマチ), osteoarthritis (变形性関節症)

\section{はじめに}

当科における術後 10 年以上経過した人工膝関節置 換術（以下 TKA）の長期成績を調查し，OA，RA 別
に比較検討したので報告する.

\section{対象及び方法}

1976 年より 1988 年までの間に当科にて行われた 
TKA は 64 例 98 膝で, 変形性膝関節症（以下 OA） が 23 例 36 膝, 慢性関節リウマチ（以下 RA）が 41 例 62 膝であった，追跡可能例は 49 例 79 膝で, 調查 時 13 例 20 膝の死亡が確認された。このうち直接検診 が可能であった 23 例 36 膝を対象とした。

直接検診例の内訳は, 男性 1 例 1 膝, 女性 22 例 35 膝, OA 10 例 16 膝, RA 13 例 20 膝, 手術時平均年 齢は OA 68 歳（60～78 歳), RA 54 歳（35〜66 歳）, 術後平均観察期間は OA 12.0 年（10１4 年), RA 11.4 年（10〜15 年）であった. TKA の使用機種は, OA 例では岡山大式 Mark II 3 膝, Mark III 8 膝, Kinematic stabilizer 3 膝, その他 2 膝, RA 例では 岡山大式 Mark II 2 膝, Mark III 12 膝, PCA 6 膝で, OAの 4 膝を除き全例セメントレスであった.

評価方法は, 臨床評価として術前, 調查時の三大学 膝機能試案 (以下三大学) と, 術前, 術直後, 調查時 の屈曲, 伸展角度を調査した.

またX線学的評価として，各コンポーネントの loosening と sinking の有無を調查した. loosening は幅 $2 \mathrm{~mm}$ 以上の全周性の骨透亮像を示すものか, 明らかな不安定性を有するあのとし, sinking は設置
角度の 5 度以上または $5 \mathrm{~mm}$ 以上の変化を示すあの とした.

また術後合併症を，追跡可能例 49 例 79 膝を対象と して調查した.

以上を OA, RA 別に paired $\mathrm{t}$-test, unpaired $\mathrm{t}$ test, $\chi^{2}$ 検定を用いて, 統計学的に比較検討した。

$$
\text { 結果 }
$$

術前及び調查時の三大学点数は, OA 群が術前平均 41 点から調查時平均 73 点に, RA 群が術前平均 40 点から調查時平均 63 点と改善していた（図 1). 各項 目では, OA 群では疼痛, 伸展不全, 変形, 歩行能力 が, RA 群では疼痛, 伸展不全, 日常動作が改善して いた. OA 群と RA 群を比較すると, 術前の三大学点 数では特に差を認めなかったが, 調查時三大学点数は RA 群に比べて OA 群が有意に高かった（p<0.01）.

$\mathrm{OA}$ 群と RA 群の点数差は歩行能力の差であった.

調查時の三大学点数 85 点以上を excellent, 70 点 から 84 点を good, 60 点から 69 点を fair, 59 点以下 を poor とすると, OA 群は excellent が 19\%, good が $44 \%$, fair が 19\%, poor が 19\%であった. RA 群

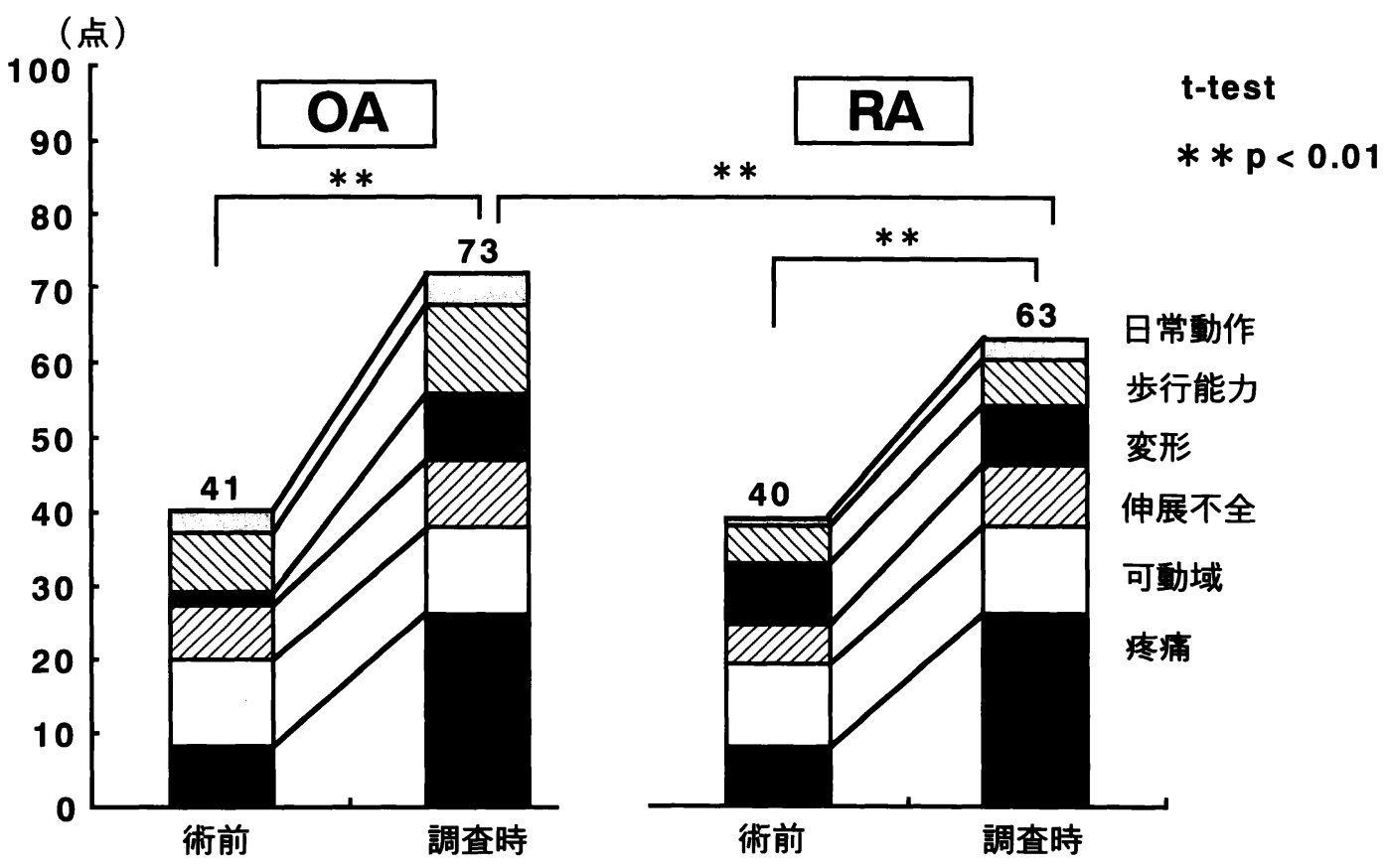

図 1 術前・調查時の三大学点数 
は excellentはなく, good が 15\%, fair が 60\%, poor が 25\%であった（図 2 ).

術後屈曲角度, 伸展角度の推移を図 3 に示す. OA 群において，屈曲角度は有意差を認めなかったが，伸 展角度は術前に比べて術直後, 調查時共に有意に改善 していた（paired t-test $\mathrm{p}<0.01$ ). RA 群においては, 調査時屈曲角度は術前, 術直後と比べて有意に低下し ていた（paired t-test $\mathrm{p}<0.01$ )。伸展角度は, OA 群

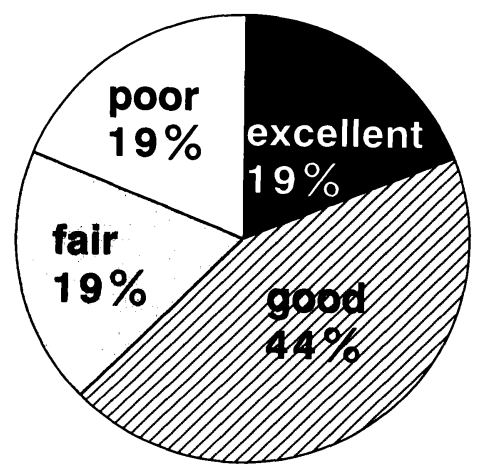

OA
と同様に術前に比べて術直後, 調査時共に有意に改善 していた（paired $\mathrm{t}$-test $\mathrm{p}<0.01$ ).

術前屈曲角度と術後屈曲角度との関連を検討した。 OA 群において, 術直後屈曲角度は術前屈曲角度と正 の相関を示した. また術後 10 年以上経過した調查時 屈曲角度も，同様に術前屈曲角度と正の相関を示した。 RA 群においても，結果は同様であった（図 4 ）.

X線学的評価では, OA 群は loosening は認めず,

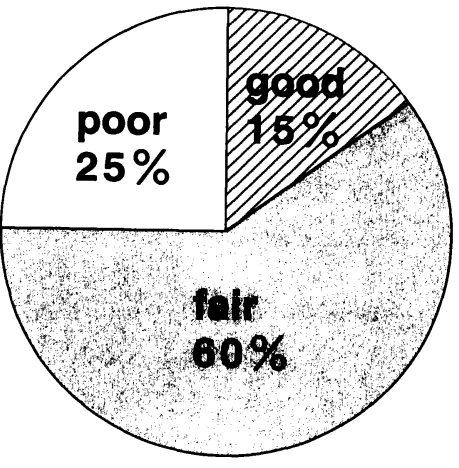

RA

図 2 調查時三大学点数
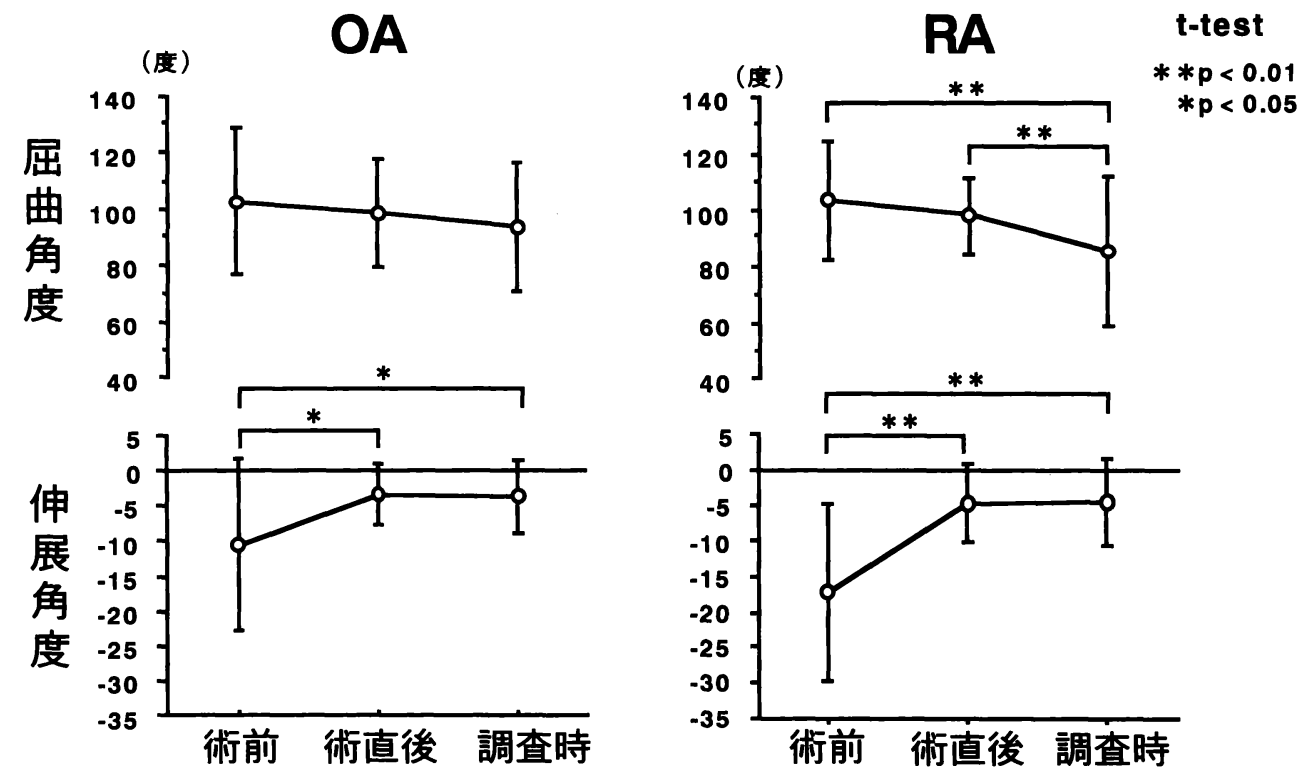

図 3 術後届曲角度, 伸展角度の推移 

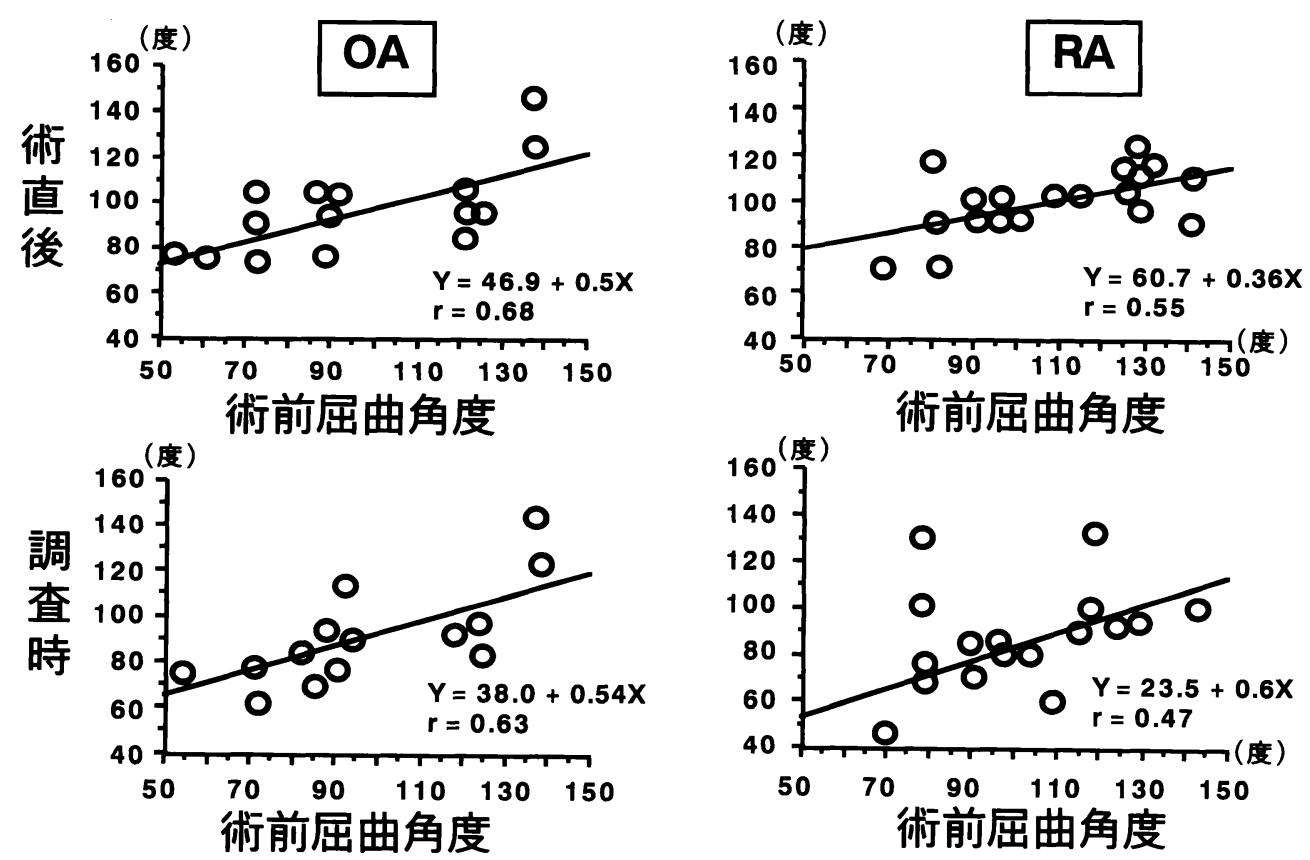

図 4 術前屈曲角度と術後屈曲角度との関連

脛骨側に sinking を 1 膝認めた。 RA 群は大腿骨側に loosening を 2 膝, sinking を 1 膝, 脛骨側に sinking 3 膝に認めた。 X線上の loosening や sinking は, OA 群は 16 膝中 1 膝 $(6 \%)$ に, RA 群は 17 膝 中 6 膝 $(35 \%)$ に認め, RA 群で有意に出現率が高かっ た $\left(\chi^{2}\right.$ 検定 $\left.\mathrm{p}<0.05\right)$.

追跡可能例 49 例 79 膝を対象とした術後合併症は, OA 群は, aseptic loosening はなく感染を 1 例 1 膝 に認め人工関節を抜去した．RA 群は aseptic loosening 5 例 7 膝に, 後方脱臼を 1 例 1 膝に認め, 6 例 8 膝全例に再置換術を施行した，感染は 2 例 2 膝に認 め, 人工関節を抜去した. RA 群は OA 群に比べて, 術後合併症を多く認めた $\left(\chi^{2}\right.$ 検定 $\left.\mathrm{p}<0.05\right)$.

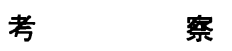

TKA の長期成績において, 多関節障害や骨粗鬆症 のため, RA はOA より成績が悪いと言われている. 勝呂ら ${ }^{4)}$ は, 岡山大式 Mark II 76 膝の平均 12.2 年の 長期成績において, RA 群は 5 年以上経過すると徐々 に成績が低下すると報告した。 三大学点数は $\mathrm{OA}$ 群 78 点, RA 群 69 点で, X線上の sinking を 8 膝 $24 \%$
に認め全例 RA であり, 再置換術は 5 膝で全例 RA であったと述べている，私たちの症例においても術後 臨床成績, X線上の loosening や sinking の出現率, 術後合併症の発生数において RA 群は OA 群に比べ て明らかに劣る結果を示した。

以上の結果から，横山ら ${ }^{5}$ の報告どおり RA 膝に対 するセメントレスTKA には限界があると考えられる. 現在わたし達は bone ingrowth 固定とセメント固定 両方の選択が可能な機種を用い, 高度の骨粗鬆症を示 す症例ではセメント固定を行っている.

術後屈曲角度に影響を与える因子として, 龍ら ${ }^{3)}$ は, 術前屈曲角度, 疾患, 術後膝蓋骨の厚さ, 術後 joint line の高さ, 使用機種, 手術手技や後療法などをあげ ている．このうち術前屈曲角度が術後屈曲角度と相関 を示したとする報告は多い(1)2) が，いずれも術後短期 の報告であり，長期的な関連は不明であった，今回術 後 10 年経過した届曲角度が, 術前屈曲角度と OA, RA ともに正の相関を示したことから, 屈曲角度が悪 くなる前に手術することが長期的な結果からも重要で あると考えられた。 


$$
\text { ま と め }
$$

1. 当科における術後 10 年以上経過した人工膝関 節置換術の成績は, OA 群, RA 群とも術前より改善 していた.

2. 術後臨床成績, X線上の loosening や sinking の出現率, 術後合併症の発生数において RA 群は OA 群に比べて明らかに劣る結果を示した。

3. 術後 10 年以上経過した届曲角度が, 術前届曲 角度と正の相関を示したことから，屈曲角度が悪くな る前に手術することが長期的な結果からも重要である と考えられた。

\section{参 考 文 献}

1）藤森十郎ほか：RA に対する各種人工㮏関節置換術之 術後可動域. 整形外科, $44: 597-604,1993$.

2) Harvey, I. A. et al. : Factors affecting the range of movement of total knee arthroplasty. J. Bone Joint Surg., 75-B : 950-955, 1993.

3）龍順之助ほか：人工膝関節置換術後の可動域を左右す る因子. 日関外誌, $13: 109-116,1994$.

4) 勝呂 徹, 守屋秀繁: セメントレス人工関節の長期成 績. 関節外科, $12: 264-270,1993$.

5）横山良樹, 井上 - : 岡山大学式人工膝関節 (Mark II ) の 10 年以上の成績とその問題点. 関節外科, 12 : 281-288, 1993. 